\title{
Research on Smart Community Planning of Yishanwan, China towards New Urbanization
}

\author{
Dang Anrong ${ }^{1}$, Li Gongli ${ }^{2}$, Li Juan ${ }^{1 *}$, Kong Xianjuan ${ }^{2}$ \\ 1 School of Architecture, Tsinghua University \\ 2 Department of Smart City, Beijing Tsinghua Tongheng Urban Planning \& Design Institute \\ * Corresponding Author, Email: Lijuan14@mails.tsinghua.edu.cn
}

Received 5 May, 2015; Accepted 20 August, 2015

Keywords: New Urbanization, Informatization, Smart Community, General Framework, Sharing Platform

\begin{abstract}
Under the guidance of the China national development policy of new urbanization, this research explores the approach of how to promote the development of new urbanization through the construction of smart community by taking the community planning of Yishanwan, Jiangxia District, Wuhan as an example. Based on the practical experience of the planning and construction of a smart city, a general framework of smart community planning of Yishanwan is put forward in this paper. The framework consists of five-layer components, which are the base layer, sharing layer, application layer, service layer and portal layer. An information center and a security system are designed to conduct the integration of the five layers. With the instruction of the framework, it is expected to achieve four targets: the construction of the infrastructure, the establishment of a sharing platform, the research and development of an application system and the development of a service portal. With the achievements implemented, the smart Yishanwan community will be founded.
\end{abstract}

\section{BACKGROUND AND DEMAND ANALYSIS}

\subsection{Background of Smart Yishanwan planning}

In the "China National Planning of New Urbanization (2014-2020)" which was published in March 2014, it claims to promote the development of green city, smart city, humanistic city and to improve the inner equality of the city comprehensively. It is obvious that the construction of smart city has escalated into a national strategy and become a significant method of promoting new urbanization and achieving sustainable development (Xi and Zhen, 2014). In the chapter of "promoting the construction of smart city", it claims to coordinate the physical resources, informational resources and the intellectual resources of urban development, and to facilitate the innovative applications of new generation information technology, such as the internet of things, big data and cloud computing, so that they can be integrated with the economic and social development effectively. In the meantime, it also proposes to promote the trans-departmental, trans-sectoral and trans-regional sharing of government affairs' information and collaboration of business, and to enhance the socialized exploitation and application of informational 
resources, and generalize intelligent information applications and new information service patterns. With all those efforts mentioned above, it is expected to achieve the informatization of management of urban planning, the intellectualization of infrastructure, the facilitation of public service, the modernization of industrial development and the refinement of social governance. Finally, it emphasizes the importance of strengthening the security capacity of a city's vital information system and pivotal information resources. In the chapter of "carrying out pilot demonstration program", it claims to go on with the pilot program of promoting a creative city, smart city and low carbon city.

In recent years, the planning and construction of smart city has become one of the key directions of Chinese urbanization development. From January 2013, Ministry of Housing and Urban-Rural Development of the People's Republic of China (MOHURD) has selected two groups of 193 cities (districts, counties, towns) to carry out the national pilot demonstration program of smart city, and the selection work of a third group of national pilot demonstration cities is under way. On the one hand, those major initiatives taken by MOHURD meet the needs of the future development of new urbanization. On the other hand, it is an inevitable consequence of the informatization development at present in China.

According to the latest "statistical report of status of China Internet network development" published by China Internet Network Information Center (CNNIC), as of December 2014, the amount of Chinese net citizens is 649 million, among them, there are 557 million mobile phone net citizens, and Chinese Internet penetration is at $47.9 \%$. It is quite encouraging that the perspective of China's informatization development is very promising in view of the nearly 10 years of statistical data and the level of informatization increasing year by year (Figure 1). But compared with some developed countries in the world, there is still much more room to improve.

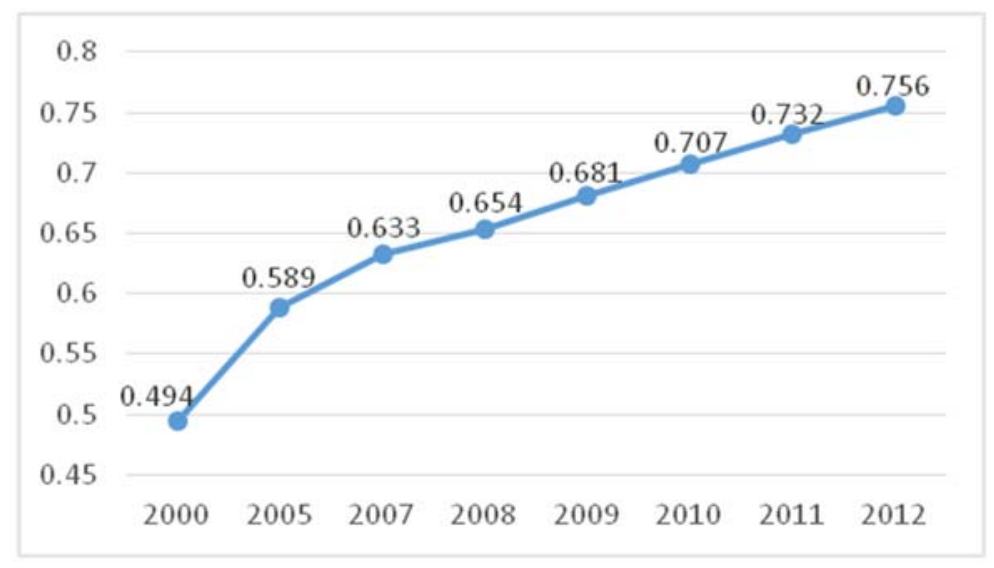

Figure 1. Change of Informatization Development Index of China (IDICN)

Data source: National Bureau of Statistics of the People's Republic of China,

http://www.stats.gov.cn/tjzs/tjsj/tjcb/dysj/201405/t20140506 549559. html

Additionally, among the reports of the 18th national congress of the Communist Party of China, the authorities have made an important policy of promoting the synchronous development of informatization, new industrialization, agricultural modernization and new urbanization, which makes the construction of informatization a national strategy. It is considered as a necessary measure to keep up with the development trends of the era. China has stepped into the middle and later period of industrialization, only 
the profound fusion of industrialization and urbanization can constantly promote the process of socialist modernization. In the meantime, new urbanization and agricultural modernization should coordinate with each other, since both of them are the breakthrough of the development of rural areas and agriculture, and they have to rely on each other and promote each other. If only urbanization is relied on, and the importance of agriculture modernization is neglected, it will be difficult to change the condition of rural areas fundamentally. Furthermore, in the process of the development of new industrialization, new urbanization and agriculture modernization, it is informatization that can facilitate and lead them (Figure 2). Only if we follow the general developing trend of the information society, think on the basis of the thought pattern of informatization and move along the development approach of informatization, can we advance and guarantee the development of new industrialization, new urbanization, and agricultural modernization. With all those efforts, we can realize the leap-forward in development of social productivity, achieve the goal of building a well-off society comprehensively and realize the construction of a beautiful China.

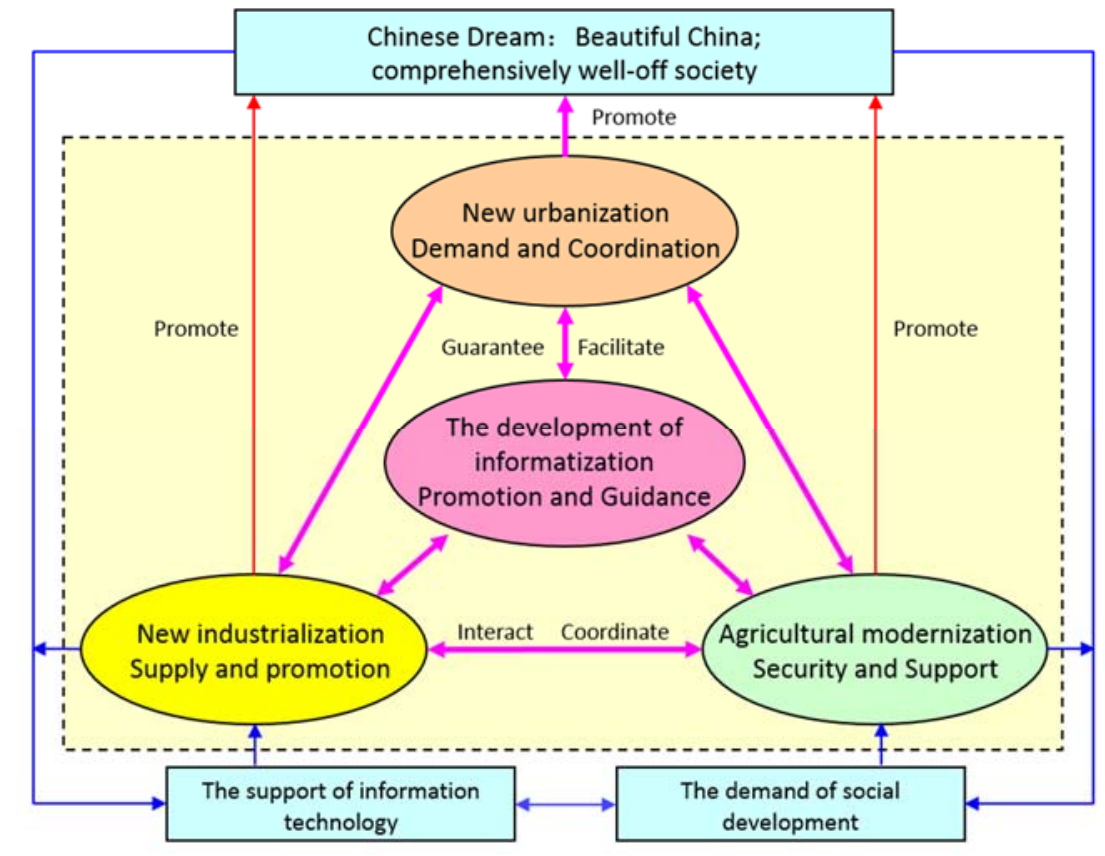

Figure 2. The synchronous development of informatization, new industrialization, agricultural modernization, and new urbanization

\subsection{Demand analysis of Smart Yishanwan}

The inevitable consequence of the profound fusion of informatization, new industrialization and new urbanization is the formation of smart city (Mao and Li, et al., 2013; Li , 2014). Smart city is based on the Internet of things and cloud computing and its core idea is to form the Internet of things through equipping every object of urban life with sensors. The Internet of things is integrated by super computers and cloud computing, thereby implementing the integration of a digital city and city systems_( $\mathrm{Li}$ and Shao, et al., 2011). The construction of smart city can not only provide more efficient services for residents by improving the infrastructure, but also will motivate the advance of the innovative ability of society and economy, integrating the concept of sustainable development into the development of cities (Chourabi and Nam, 2012). 
At present, in the process of vigorously promoting China's new urbanization, the construction of smart city will contribute from different aspects, such as technology innovation, infrastructure, economic transformation, social management and so on (Xi and Zhen, 2014). Smart community is further a concrete embodiment of the structure of smart city and becomes a basic composition unit of a smart city (Jiao, 2013). Smart community has inherited the construction experience of smart city, which will apply to many kinds of up-to-date information technology comprehensively on the community scale, exploit many kinds of information resources and establish a community public data resource center, so as to achieve intelligence of community management, community governance and community social service.

Yishanwan community is located in Jiangxia District, Wuhan, Hubei Province, China (Figure 3). As it plans the community space layout and industrial layout in the new comprehensive planning, it also urgently calls for the development of community informatization. It believes that only deepening the application of information technology in all fields of new community, fully excavating, real-time integrating and effectively allocating the community resources can realize the integration of urban and rural areas' overall development. Therefore, under the background of the synchronous development of informatization, new industrialization, agricultural modernization and new urbanization, the construction of Yishanwan smart community towards new urbanization is to follow both the trend of the era and the approach which most conforms to the local developing expectations. According to the experience of the construction of smart city, the demand of building Yishanwan smart community is embodied in four aspects: the construction of informatization infrastructure, informatization management, informatization services and the construction of informatization mechanisms.

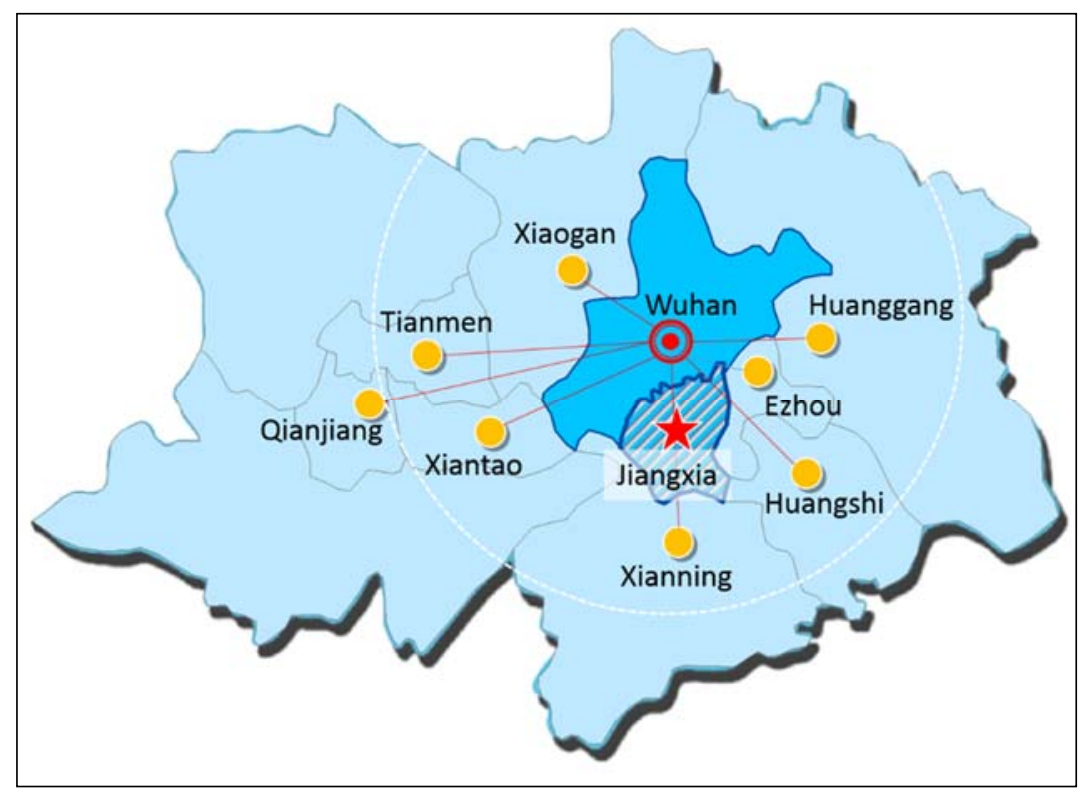

Figure 3. The location and relationship of Jiangxia district and surrounding cities 


\section{GENERAL FRAMEWORK AND MAIN TASKS}

\subsection{The general framework of Smart Yishanwan}

According to the demand of informatization development of smart community, the general framework (Figure 4) of Smart Yishanwan consists of five-layer components, including base layer, sharing layer, application layer, service layer, and portal layer. An information center and a security system are working on the integration of the five layers. The framework can be summarized as a project of "Six Ones", that is organizing one information center, building one base layer (a set of infrastructure), one sharing platform, one application and service system, one information portal and one security system.

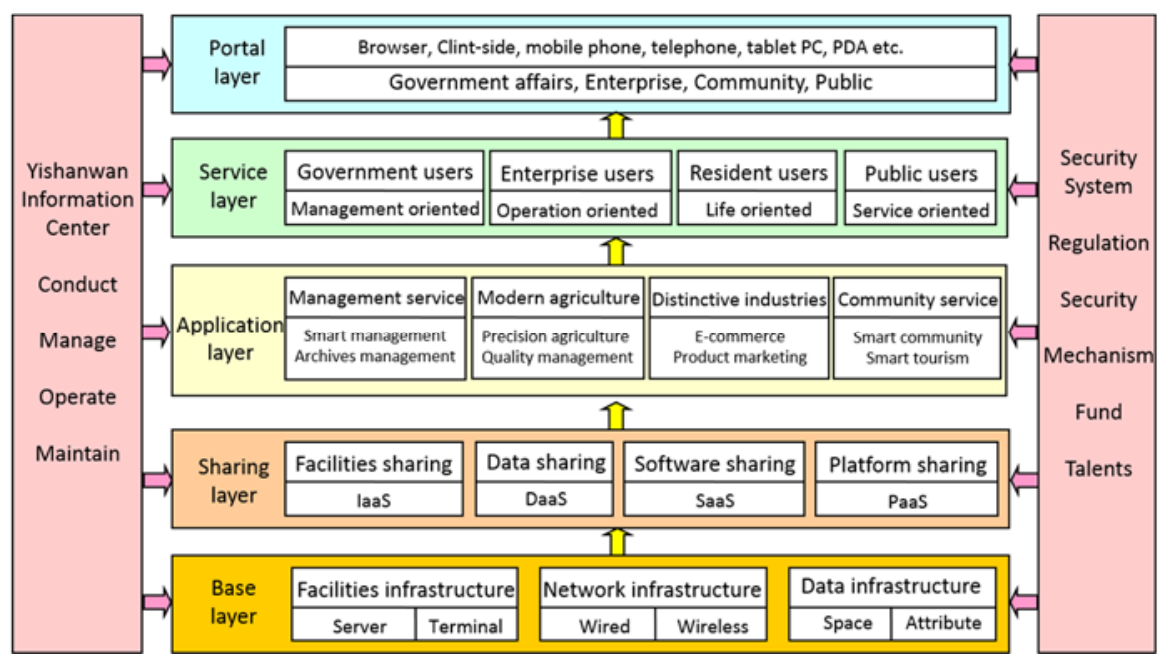

Figure 4. The general framework of Smart Yishanwan community

(1) The information center. A professional institution is required to be in charge of the kinds of work of a Smart Yishanwan community, which includes project planning, organizing and implementing, constructing and managing, and operating and maintaining. Taking account of the scale of Yishanwan community and the efficiency and benefit to operate and maintain the center, it is appropriate to authorize the information center of Jiangxia District to undertake the task.

(2) The infrastructure layer. This is required to sense, collect, transmit, store, manage and update the community data of Smart Yishanwan, and realize the interconnection and interwork of diverse application system data, as well as to provide data service and support for the upper layer through intelligent processing including data connecting, data evolving and data maintaining.

(3) The information sharing layer. This aims at gathering different kinds of intelligent application services and establishing application oriented public service through the middleware of diverse software. As the foundation of building all sorts of typical intelligent applications of Smart Yishanwan, the sharing layer will realize the sharing of all resources of a Smart Yishanwan community including facilities, data, software, platform and so on.

(4) The application and service layer. It works directly for users of different levels and terminal equipment, and provides specific intelligent applications and services for different types of users of Smart Yishanwan 
community, including four aspects which illustrate the useful effect of the informatization and the synchronous development of informatization, new industrialization, agricultural modernization and new urbanization, that is government affairs management service, development of modern agriculture, development of characteristic industries, and smart community service.

(5) The community portal. This integrates the applications of government affairs, enterprises, community and the public in the form of a portal, which will be published by means of browser, client-side, smartphone, network TV, tablet PC, and PDA etc., providing service and support for government affairs, enterprises, community and the public of the service layer.

(6) The implementation and security system. It involves the regulation, standard, security, fund and talents, and therefore should play a part throughout the whole process of data sensing, data transmission, data storage, data processing, data display and data application.

\subsection{The main tasks of Smart Yishanwan}

The main tasks of Smart Yishanwan consist of the construction of infrastructure, the establishment of the sharing platform, the research and development of an application system and the development of a web portal. The four main tasks can be divided into eight aspects which refer to facilities infrastructure, network infrastructure, spatial data infrastructure, information sharing platform, government affairs management service, development of modern agriculture, development of smart community and smart community portal.

(1) Facilities infrastructure. The fundamental facilities are the base of the whole information system. In the first place, it is a pre-requisite to guarantee that each link is able to employ a computer to complete the basic work in the whole information system, then it is required to establish a server which will deal with a variety of businesses and the corresponding storage system, so as to implement the hardware system based on the network architecture. In the end, a network system which connects all the business terminals, servers and storage devices comes into being, achieving the informatization and networking of all businesses. We finally design the facilities infrastructure of Smart Yishanwan community which includes four categories: the basic server, the network storage, the computer terminal and the mobile application terminal.

(2) Network infrastructure. The composition of the network infrastructure of Smart Yishanwan mainly includes two parts which are the information sensing facilities and information transmission facilities. Information sensing facilities are the facilities and technology for information collection, which are located in the front-end of the informatization system, such as remote sensing technology, radio frequency identification (RFID), Global Navigation Satellite System (GNSS) terminal, sensor and video capture terminal, etc. Information transmission facilities mainly refer to wired and wireless networks, including fiber optic backbone network, wireless communication network, WLAN (Wireless Local Area Networks) in key areas and related servers, network terminal facilities and technology. Essentially, the information transmission facilities are the internet of things' system including a core network, access network and extended network, which consists of a sensor network composed of ubiquitous new sensing facilities and next generation internet. It is able to sense and transmit information of components, facilities, equipment, and 
humans in real time.

(3) Data infrastructure. The foundational database system of basic space, industries, economy and population should be set up based on geospatial information. According to the concept of "One Map", it will be beneficial to integrate all sorts of economic and social development data and establish one data center of Smart Yishanwan which can uniformly provide visualized decision analysis and a data sharing service for the typical applications of the Smart Yishanwan community. On the basis of related regulations of building spatial data infrastructure, taking the present development situation and the demand of Yishanwan informatization as a starting point, and following the trend of future development of information technology at the same time, the data infrastructure of the Smart Yishanwan community will be composed of a series of subsystems including data collection, database management, data access, system management, data backup, staff management, interaction webpage and data export, etc.

(4) Information sharing platform. The development of various industries and businesses has a strong demand for the exchange and service of public information resources. To meet the demand, an open and shareable supply service platform should be constructed, realizing the integration of a dynamic information service for the Smart Yishanwan community, and managing, sharing, exchanging all sorts of public information of community management, community production and life. The sharing and service platform of Smart Yishanwan is the foundation and key to achieve smart community, and the fundamental goal of constructing this platform is to adopt a uniform data exchange format realizing data exchange and information sharing between different information systems. On the basis of the achievement of the above goal, it can be guaranteed that each application system will be able to be integrated into one basic platform which is easy to integrate, easy to maintain and extensible, making it convenient to upgrade the business process in order to satisfy new business requirements.

(5) Government affairs management service. To improve the intelligence level of office working, serving and decision-making of Yishanwan community government and each functional department, and form an efficient, agile and convenient new government realizing smart government affairs management, we should make full use of the internet of things, mobile internet and technology of data excavation and knowledge management etc. Through the establishment of smart government affairs, the governance pattern will be transformed from "management oriented" to "service oriented", improving the efficiency of handling the official business of the Yishanwan community government. It will also improve governance transparency, strengthen the cultivation of an incorruptible government and improve the governing capacity and the ability of scientific decision-making. Meanwhile, it plays an important role in promoting policy advocacy and public education.

(6) The development of modern agriculture. The informatization development of Yishanwan modern agriculture takes the demands of Yishanwan as a starting point and accelerates the profound fusion of informatization and agriculture. The aim of modern agriculture is to develop one kind of agriculture which is land-intensive, technology-intensive and ecologically-circular, to promote the deep processing of agricultural products and strengthen quality management. Therefore, the core idea of modern agriculture is to promote automatic production, industrialized operation and brand marketing of agricultural products, in order to improve comprehensive productivity, competitive capacity and sustainable developing capacity of 
agriculture, and enhance the vitality of economic development as a result.

(7) The development of smart community. To promote the construction of the smart community of Yishanwan, it needs to integrate government a web portal with a service hotline. Based on the establishment of a community residential service hotline, residential portal and community information service station, we build the smart community connected by a convenience card, government affairs data center or other public service platform. The development of a smart community will provide lots of services for community residents including convenient information inquiry, social insurance, on-line education, tele-medicine, smart culture, and so on, as well as a change of life style, learning style, and working mode gradually. It will enhance the informatization level of community life in every way, forming a high quality, convenient, happy and comfortable living environment.

(8) The development of a community portal. Supported by the new generation of information technology, the web portal of the Yishanwan community will integrate various government resources and various application services in accordance with the unified planning, unified standard and unified architecture, building a smart community portal with open information, efficient service, a good user experience and accessibility for the mobile intelligent terminal. With the above efforts, the portal will be able to achieve the function of information service provider, e-government affairs, online service and interaction between government and the public, creating a one-stop and comprehensively intelligent service platform. We attempt to realize three goals with the construction of the web portal: all coverage of information services, one-stop service of government affairs and a well-found interaction system between government and the public.

\section{INFORMATION SHARING AND APPLICATION}

\subsection{Information sharing platform of Smart Yishanwan}

The information sharing platform of the Smart Yishanwan community can be supported by SOA (Service Oriented Architecture) and cloud computing. With the support of such technology, we construct a "service center" applying the hierarchical structure and assemble all kinds of "atomic services" of the center through a "service factory" so as to create certain functional services which meet the actual demand. And these functional services will be published based on the mode of the "service market" and can be employed directly by different departments of the smart community which will contribute to building all kinds of application systems. The sharing platform contains four subsystems: data management system, public service system, sharing and exchange system, and operation and maintenance system. Figure 5 has demonstrated the architecture of the information sharing platform. Each subsystem of the information sharing platform has their own function in the whole architecture (Figure 5):

(1) Data management system. This is responsible for producing, updating, maintaining and daily managing the data of the sharing platform of the Smart Yishanwan community. Data maintenance personnel are the main users of this system.

(2) Public service system. On the basis of the unified spatial platform, this can realize query, statistics, analysis and applications, taking advantage 
of a location based service. At the same time, the users from professional departments can publish and upload thematic information of their departments, provide all sorts of data services and secondary development interfaces and develop business application systems based on the data resources.

(3) Sharing and exchange system. This demonstrates the data resources the platform contains and data service and function service it provides, so that users can rapidly search the data resources included and figure out how to use those resources. The staff from certain departments can edit, update and maintain the thematic data online, which the departments take charge of. Data management personnel of each department are the main users of the sharing and exchange system.

(4) Operation and maintenance system. This system is an important component to guarantee the regular and safe operation of the platform. It is responsible for the operation, management and maintenance of the whole platform, including the monitoring of service, resource allocation of the system and physical condition of the platform. The managers of the platform are the main users of this system.

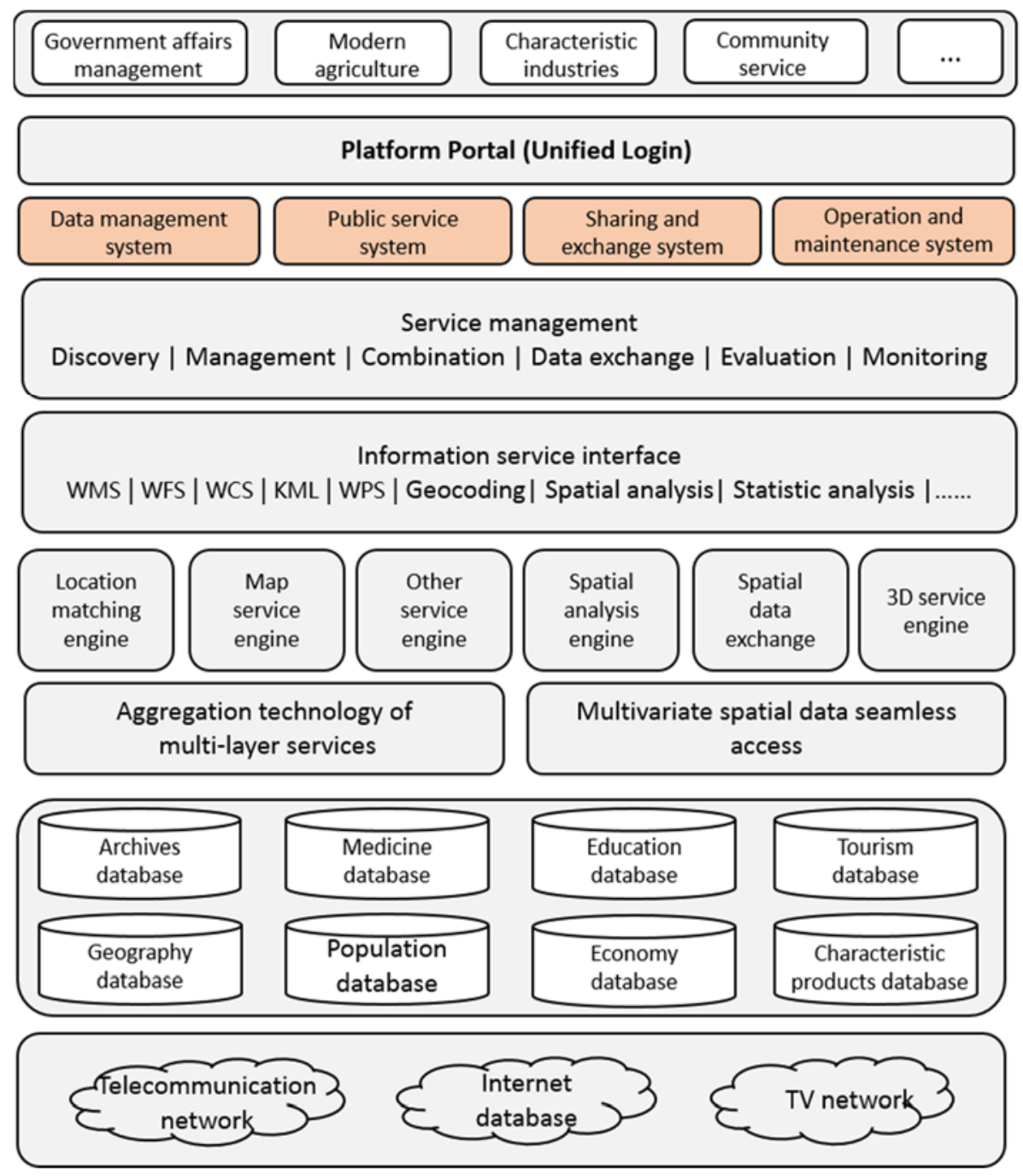

Figure 5. The architecture of information sharing platform of Smart Yishanwan community 


\subsection{Application of characteristic industries}

The application of characteristic industries of Smart Yishanwan is mainly reflected in characteristic product marketing and smart tourism.

(1) Characteristic product marketing system

To develop smart industries is an important measure to promote the profound fusion of informatization and industrialization and is a significant approach to promote the optimization and upgrading of the Chinese industrial structure, more importantly, it is an indispensable part of the smart city (Feng and Jiang, 2011; Jin, 2012a). The development of Yishanwan smart industries focuses on the informatization of characteristic industries, facilitating the fusion of industrialization and informatization based on its own characteristics. It encourages enterprises to carry out networked, digital and intelligent upgrades on product innovation, product deep processing and product marketing, so as to enhance the impact of informatization on guiding and supporting the traditional industries. Compared to the traditional industries, the smart industries put more emphasis on the intellectualization, including the intellectualization of research and design, the intellectualization of manufacture, the intellectualization of operation and management and the intellectualization of marketing (Jin, 2012b).

In order to illustrate the development of the smart industries of the Smart Yishanwan community, we take a characteristic product marketing system as an example. The Yishanwan community produces lots of characteristic products, like rice, lotus root starch, lotus, etc. To expand their sales market, we must transform the traditional marketing channels and turn to the new e-commerce mode to improve the communication efficiency of information. The characteristic product marketing system takes charge of collecting, organizing, classifying, and analyzing the information of all sorts of characteristic products and expands their distribution channels relying on a well-run e-commerce platform such as TaoBao and Alibaba. The system needs to provide a platform for the enterprises, organizations and individual users to display products, to trade and to publish product information. Therefore, the system should have the function of commodity categories and display, commodities management, order management and website information release management (Figure 6), aiming to promote the circulation and transaction of the characteristic products and provide impetus for community economic development.

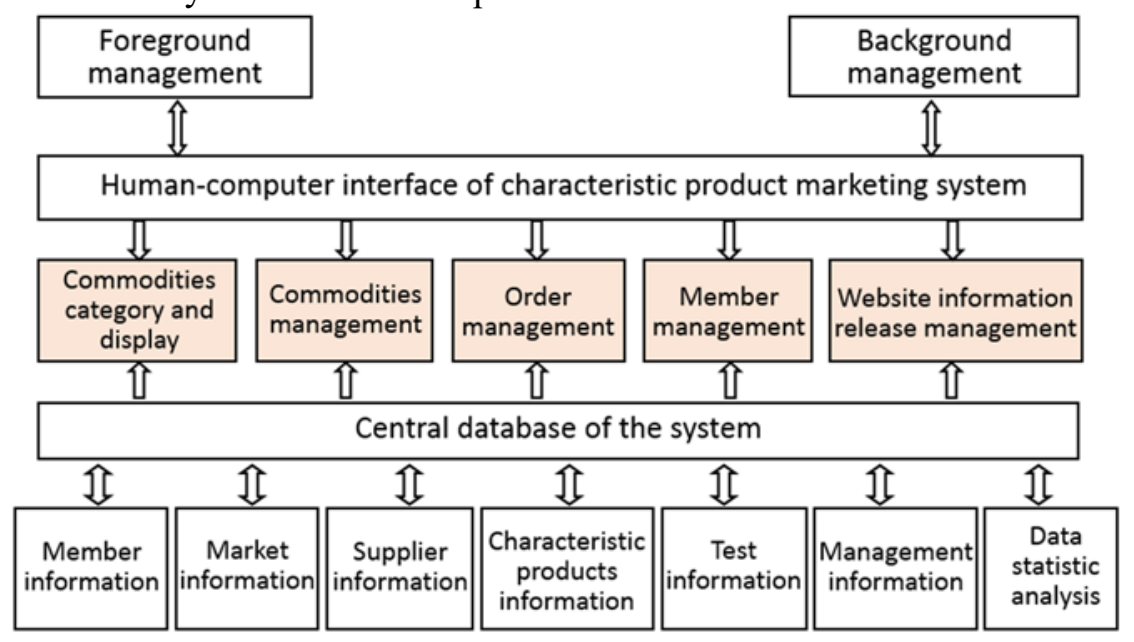

Figure 6. The structure of the characteristic product marketing system of Smart Yishanwan 
(1.1) Commodity categories and display. These realize the category management and hierarchical display of the commodities so that the browsers can reach their target goods quickly and conveniently.

(1.2) Commodities management. This improves the accessibility by modifying the classification of commodities along with the change of the characteristic products.

(1.3) Order management. This adds the features of new order production, order disposing records, order inquiry and order statistics etc., to improve the user experience.

(1.4) Member management. Users can apply to be registered members of the platform and by storing the information and shopping records of the members we can establish a valuable customer database.

(1.5) Website information release management. This publishes the information of the characteristic products, enterprises, supply and demand, business negotiations and price etc., to improve the transparency of information and resource utilization rate, simultaneously promoting the products transaction and industrial development.

\section{(2) Smart tourism information system}

Smart tourism is one significant subsystem of a smart city where we can take advantage of the existing achievements of a smart city to realize some functions of smart tourism. Smart tourism on the one hand aims at satisfying the personal demand of tourists; on the other it achieves the goal of combining public service and public management of tourism efficiently (Zhang, Li, et al., 2012). The Smart Yishanwan community focuses on the leisure tourism; by developing smart tourism it will accelerate the development of characteristic industries, as well as be an effective way to improve the comprehensive competitiveness of Yishanwan characteristic industries.

The Yishanwan smart tourism service system unites local unique tourism resources and makes the best of cloud computing and the internet of things by means of laying internet, WLAN, smart terminal facilities and adopting electronic ticket systems and intelligent navigation systems. A smart scenery spot will be constructed so as to improve the attraction of Yishanwan tourism resources and accelerate the development of the tourism industry. A Yishanwan smart tourism information system mainly contains tourist services and tourism management. (Figure 7)

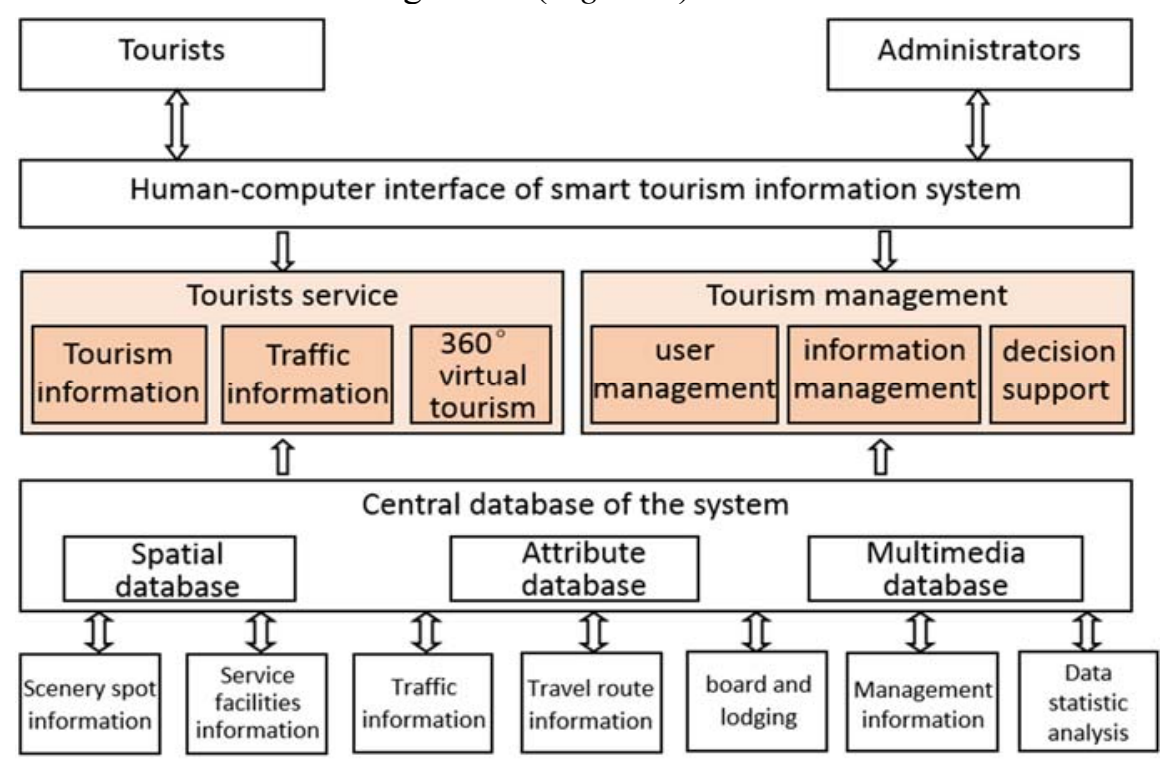

Figure 7. The structure of the smart tourism information system of Smart Yishanwan 
(2.1) Tourists service. The functions which serve the tourists contain tourism information, traffic information and 360 degree virtual tourism. Tourism information service: displaying an overall view of Yishanwan's abundant natural and cultural landscape, providing detailed information of scenic spots and accommodation, as well as food, shopping and medical treatment which are accessible through several kinds of inquiry modes. Traffic information service: taking full advantage of the resource of Jiangxia District and Wuhan traffic information, offering information queries about flight, train, coach and bus, displaying the condition of traffic routes dynamically. 360 degree virtual tourism service: tourists can stroll the zone virtually under the system through some simple operations like full width display, zooming in, zooming out, roaming and Hawkeye navigation. Through these functions, it will help the tourists experience 360 degree virtual tourism so that they can quickly find zones of interest or specific targets.

(2.2) Tourism management. The functions which serve the tourism administrators contain user management, information management and decision support. User management: the administrators can supervise the whole system after logging in and they can supervise the user permission, travel information, travel route and user messages. Information management: it realizes the functions of travel information addition, new scenic spot approval, information modification and removal, and sets the limits of accessibility authority to professionals or the public based on the specific contents. Decision support: this builds the tourism resource evaluation model, zone capacity model and development evaluation model, in order to provide support for reasonable analysis and long-term planning.

\section{CONCLUSION}

This research on smart community planning of Yishanwan towards new urbanization aims at the synchronous development of informatization, new industrialization, agricultural modernization and new urbanization. We are trying to make great use of advanced technologies such as the internet of things and cloud computing, in order to achieve human-oriented development and accelerate research progress toward leading technologies with the drive of service-oriented and ubiquitous networks. At the same time, we are making efforts to transform the advanced achievements of informatization into the fields of production, life and management, so as to provide more convenient and flexible applications and service modes for community public management and to offer more efficient and intelligent methods of production and operation for economic development. The development of the Smart Yishanwan community will propel the construction of the infrastructure of the internet of things and positively facilitate the fulfillment of some particular programs including archives management, quality supervision of agricultural products, tourism service and smart community service etc., in order to effectively promote the innovation of community operating mechanisms and management modes, making the Yishanwan community a national paradigm of new urbanization. We hope this framework and method of creating a smart Yishanwan community can be a valuable reference for other communities. 


\section{REFERENCES}

Chourabi and Nam (2012), "An Integrative Framework", Proceedings of the 45th International Conference on System Science, Hawaii, 2389-2397.

Feng, M.Y. and Jiang, L.Z. (2011). "On the Intelligent City and Intelligent Industry Development-Taking Nanjing City as an Example", Reformation \& Strategy, (09), 127-128+155.

Jiao, J.Y. (2013). "The exploration about innovative application system of smart community service", Internet of Things Technologies, (02), 8-11+13.

Jin, J.J. (2012a). "Strategies of Smart Industry development", Technoeconomics \& Management Research, (11), 40-44

Jin, J.J. (2012b). "Analysis about the Development Status and Trends of Industrialization and Informatization Integration", Modern Industrial Economy and Informationization, (16), 74-77.

Li, D.R. (2014). "Smart city 'excavates' big data”, China Informatization, (11), 16-19.

Li, D.R., Shao, Z.F., et al. (2011). "Theory and Practice from Digital City to Smart City", Geospatial Information, (06), 1-5+7.

Mao, Z.Y., Li, Z.M., et al. (2013). "The research on the the synchronous development of industrialization, informatization, urbanization, agricultural modernization", Agricultural Archaeology, (04), 312-318.

Xi, G.L. and Zhen, F. (2014). "Strategic Research on the Development of New Urbanization through Building Smart Cities", Shanghai Urban Planning Review, (05), 26-29.

Zhang, L.Y., Li, N., et al. (2012). "On the Basic Concept of Smarter Tourism and Its Theoretical System”, Tourism Tribune, (05), 66-73. 